Pengaruh Kualitas Pelayanan Perbankan Syariah

\title{
Pengaruh Kualitas Pelayanan Perbankan Syariah \\ Terhadap Kepuasan Nasabah
}

\author{
Oleh: \\ Zaim Mukaffi \\ Ahmad Sidi Pratomo \\ Muhammad Nanang Choiruddin
}

Fakultas Ekonomi UIN Maliki Malang

\begin{abstract}
The research aims to; Analyze whether the variable partial effect of service quality on customer satisfaction on Islamic Banking in Malang, Determine and analyze whether the variable service quality simultaneously influence on customer satisfaction on Islamic Banking in Malang, Knowing which variables among the service variable most dominant influence on customer satisfaction on Islamic Banking in Malang. Analysis of the data in this study using multiple linear regression test and subsequently used the $\mathrm{F}$ test, $\mathrm{T}$ and dominant to see the effect of each.

The research results indicate that the value of F-test (3.722) > F table (2.437) this indicates that variable Tangibles, Reliability, Responsiveness, Assurance, and Empathy simultaneously (together) effect on customer satisfaction. While the partial test for Tangibles variable $(X 1)$ where $t$ test $(1232)>t$ table $(2,571)$ this indicates that Tangibles no effect on customer satisfaction. For Reliability (X2), $t$ test (3428) > $t$ table (2571), that affect the reliability of customer satisfaction. For variable Responsiveness (X3), $t$ test (.390) $>\mathrm{t}$ table $(2,571)$ Responsiveness no effect on customer satisfaction. To Guarantee $(\mathrm{X} 4), \mathrm{t}$ test $(0.549)>\mathrm{t}$ table $(2,571)$, variable warranty does not affect the customer satisfaction. For variable Empathy (X5) regression coefficient of -0103 , the $t$ test (0667) $>\mathrm{t}$ table $(2,571)$ and a variable Empathy has no effect on customer satisfaction. While the dominant variable in the quality of services that affect customer satisfaction in the city of Malang Islamic banking is variable Assurance (X4) with a contribution of $51 \%$.
\end{abstract}

Keyword: Service Quality, Satisfaction, Customer

El-Dinar, Vol. 4, No. 2, Juli 2016 


\section{Pendahuluan}

Bank merupakan lembaga keuangan yang mempunyai tugas pokok adalah menghimpun dana dari masyarakat dan memberikan kredit serta jasa-jasa lainnya dalam memperlancar arus pembayaran keuangan (Peter, 1996, dalam Soenarmi: 2012, 2). Definisi tersebut dapat diartikan bahwa bank adalah lembaga atau suatu badan usaha yang berniagakan uang. Oleh sebab itu, dalam menjalankan fungsinya, perbankan dapat meningkatkan dan mempertahankan keuntungan yang didapatnya. Beberapa fungsi vital pada perbankan saat ini adalah the trust function, the credit function, the investment/planning function, the payment function, the first of saving function, the cash managenent function, the investment banking/under writting function, the brokerage function, the insurance function.

Dengan adanya UU. No. 7 tahun 1992 tersebut maka terdapat titik terang bagi bank umum maupun BPR dalam menyediakan pembiayaan berdasarkan sistem bagi hasil yang sesuai dengan prinsip syariah (Perwaatmadja \& Dewi; 2005:61-63). Dalam undang-undang tersebut dijelaskan tentang bagaimana bank syariah sebagai institusi yang menyediakan pelayanan jasa perbankan yang berprinsip pada sistem bagi hasil. Namun demikian semua hal terkait selain dengan sistem tersebut maka perbankan syariah tetap harus patuh terhadap undang-undang Bank Indonesia (BI).

Setelah akhir tahun 2000 atau awal 2001, perkembangan perbankan syariah mengalami peningkatan yang sangat pesat, hal ini ditunjukkan oleh berdirinya Bank Mandiri Syariah (BSM), BNI Syariah, BTN Syariah dll. Disini perbankan umum/konvensional melakukan peran ganda sebagai bank konvensional itu sendiri dan bank syariah.

Kualitas pelayanan merupakan salah satu faktor yang selama ini mempengaruhi kepuasan konsumen/nasabah secara umum, dan menjadi faktor utama dalam kepuasan konsumen/nasabah sebuah perusahaan jasa. Peningkatan kualitas pelayanan sebagai salah satu motivator pengikat loyalitas konsumen adalah inti dari usaha di bidang jasa termasuk di dalamnya dunia perbankan. Sehingga pihak manajemen lebih banyak memfokuskan pada sisi ini. Penelitian-penelitian yang dilakukan oleh manajemen maupun pihak luar pun banyak yang ditujukan untuk mengukur dan menilai kualitas pelayanan guna 
menentukan strategi yang akan digunakan untuk meningkatkan kepuasan nasabah.

Oleh karena itu, penelitian ini bertujuan untuk; Mengetahui dan menganalisis apakah variabel kualitas pelayanan berpengaruh secara simultan terhadap kepuasan nasabah pada Perbankan Syariah di Kota Malang. 2) Mengetahui dan menganalisis apakah variabel kualitas pelayanan berpengaruh secara parsial terhadap kepuasan nasabah pada Perbankan Syariah di Kota Malang.3) Mengetahui variabel manakah diantara variabel pelayanan yang berpengaruh paling dominan terhadap kepuasan nasabah pada Perbankan Syariah di Kota Malang.

\section{Kajian Teori}

\section{Konsep Pelayanan}

Pelayanan merupakan bentuk pemenuhan hal-hal yang diharapkan pelanggan atas kebutuhan mereka. Bentuk pelayanan pada umumnya dibedakan atas dua macam, yaitu: (1) Pelayanan atas produk berbentuk barang, yakni pelayanan yang diberikan perusahaan atas produk yang berupa barang berwujud, dan (2) Pelayanan atas produk berbentuk jasa, yakni pelayanan yang diberikan perusahaan atas produk yang sifatnya tidak berwujud (tidak nyata). Menurut Lovelock seperti dikutip Tjiptono (2000) pelayanan/jasa dapat diklasifikasikan berdasarkan lima kriteria, yaitu: (1) Berdasarkan sifat tindakan jasa, (2) Berdasarkan hubungan dengan pelanggan, (3) Berdasarkan tingkat cutomization dan judgement dalam penyampaian jasa, (4) Berdasarkan sifat permintaan dan penawaran jasa, dan (5) Berdasarkan metode penyampaian jasa. Sedangkan menurut Moenir (1992) bentuk-bentuk dari pelayanan tersebut terdiri dari:

1. Pelayanan dengan lisan. Dalam pelayanan dengan lisan ini fungsi humas betul-betul diefektifkan sebagai kepanjangan tangan dari pemberian informasi kepada pelanggan. Dengan kata lain pelayanan lisan adalah komunikasi langsung kepada pelanggan.

2. Pelayanan dengan tulisan. Pelayanan dalam bentuk tulisan ini dilakukan berdasarkan pada jarak yang terlalu jauh antara pelanggan dengan produsen. Adapun pelayanan ini dapat digolongkan yaitu pelayanan berupa petunjuk dan pelayanan berupa reaksi tertulis atas permohonan.

3. Pelayanan dengan perbuatan. Adapun pelayan yang dilakukan dengan perbuatan merupakan tindak lanjut dari 


\section{Pengaruh Kualitas Pelayanan Perbankan Syariah}

suatu pekerjaan pada bagian pelayanan agar dapat beradaptasi langsung atau bertatap muka dengan pelanggan.

Adanya penerapan bentuk pelayanan yang diberikan, secara tidak langsung akan dapat memberikan kepuasan kepada para pelanggan.

\section{Faktor-faktor yang Mempengaruhi Pelayanan}

Agar pelayanan memiliki kualitas dan memberikan kepuasan kepada pelanggan mereka, maka perusahaan harus memperhatikan berbagai dimensi yang dapat menciptakan dan meningkatkan kualitas pelayanannya. Hasil penelitian yang dilakukan Berry dan kawan-kawan seperti dikutip Payne (2000) faktor-faktor yang mempengaruhi kualitas pelayanan dapat diidentifikasi dalam lima aspek kunci sebagai berikut:

a. Faktor fisik (tangibles): fasilitas fisik, perlengkapan, penampilan personil.

b. Reliabilitas (reliability): kemampuan melakukan layanan atau jasa yang diharapkan secara meyakinkan, akurat dan konsisten.

c. Daya tanggap (responsibility): kemauan memberikan layanan dan mem-bantu pelanggan.

d. Jaminan (assurances): pengetahuan, sopan santun, dan kemampuan karyawan menyampaikan kepastian dan kepercayaan.

e. Empati (emphaty): perhatian individual kepada pelanggan.

\section{Kualitas Jasa}

Definisi kualitas jasa berpusat pada upaya pemenuhan kebutuhan dan keinginan pelanggan serta ketepatan penyampaiannya untuk mengimbangi harapan pelanggan. Kualitas jasa adalah tingkat keunggulan yang diharapkan dan pengendalian atas tingkat keunggulan tersebut untuk memenuhi keinginan pelanggan. Dengan kata lain ada dua faktor utama yang mempengaruhi kualitas jasa, yaitu expected service dan perceived service. Apabila jasa yang diterima atau dirasakan (perceived service) sesuai dengan harapan, maka kualitas jasa dipersepsikan baik dan memuaskan. Jika jasa yang diterima melampaui harapan pelanggan, maka kualitas jasa dipersepsikan sebagai kualitas yang ideal. Sebaliknya jika jasa yang diterima lebih rendah daripada yang diharapkan, maka kualitas jasa dipersepsikan buruk. Dengan demikian baik buruknya kualitas jasa tergantung pada kemampuan penyedia jasa dalam memenuhi harapan pelanggannya secara konsisten (Tjiptono, 2004: 59). 


\section{Service Excellence (Pelayanan Yang Unggul)}

Menurut (Nasution, 2004: 49), Yang dimaksud dengan service excellence adalah suatu sikap atau cara karyawan dalam melayani pelanggan secara memuaskan.

Secara garis besar, ada empat unsur pokok dalam konsep kualitas, yaitu: kecepatan, ketepatan, keramahan dan kenyamanan. Keempat komponen ini merupakan satu kesatuan pelayanan yang terintegrasi, maksudnya pelayanan atau jasa menjadi excellent. Setiap karyawan harus memiliki ketrampilan tertentu, diantaranya berpenampilan baik dan rapi, bersikap ramah, memperlihatkan gairah kerja dan sikap selalu siap untuk melayani, menguasai pekerjaannya, baik tugas yang berkaitan pada bagian atau departemennya maupun bagian lainnya, mampu berkomunikasi dengan baik, bisa memahami bahasa isyarat (gesture) pelanggan, dan memiliki kemampuan menangani keluhan pelanggan secara professional.

\section{Pengertian Kepuasan}

Kepuasan adalah tingkat perasaan seseorang setelah membandingkan kinerja produk (atau hasil) yang ia rasakan dengan harapannya. Jadi tingkat kepuasan merupakan fungsi dari perbedaan antara kinerja yang dirasakan (perceived performance) dan harapan (expectations) (Kotler, 2000: 50).

Banyak pakar yang memberikan definisi mengenai kepuasan pelanggan atau ketidakpuasan pelanggan. Day dalam Tse dan Wilton, 1988 dalam Tjiptono (2004: 146), menyatakan bahwa kepuasan atau ketidakpuasan pelanggan adalah respon pelanggan terhadap evaluasi ketidaksesuaian atau diskonfirmasi yang dirasakan antara harapan sebelumnya (atau norma kerja lainnya) dan kinerja aktual produk yang dirasakan setelah pemakaiannya.

\section{Hipotesis}

$\mathrm{H} 1$ = Variabel-variabel kualitas pelayanan berpengaruh secara simultan terhadaj Kepuasan nasabah perbankan syariah di kota Malang.

$\mathrm{H} 2$ = Variabel-variabel kualitas pelayanan berpengaruh secara parsial terhadap Kepuasan nasabah perbankan syariah di kota Malang

$\mathrm{H} 3$ = Variabel Tangibel berpengaruh dominan terhadap Kepuasan nasabah perbankan syariah di kota Malang. 
Pengaruh Kualitas Pelayanan Perbankan Syariah

\section{Kerangka Berfikir}

Dalam penelitian ini peneliti ingin mengungkap apakah ada hubungan antara kualitas pelayanan berpengaruh secara simultan terhadap Kepuasan nasabah perbankan syariah di kota Malang. Faktor-faktor kualitas pelayanan disini sebagai variabel independen dan Kepuasan nasabah sebagai variabel dependen. Berdasarkan konsep diatas maka peneliti mencoba menguraikan dalam model konsep dan kerangka berpikir sebagai berikut; Model Konsepsi

\section{Kualitas pelayanan $\longrightarrow$ Kepuasan Nasabah}

\section{Gambar 1 \\ Model Konsep Penelitian}

\section{Model Hipotesis}

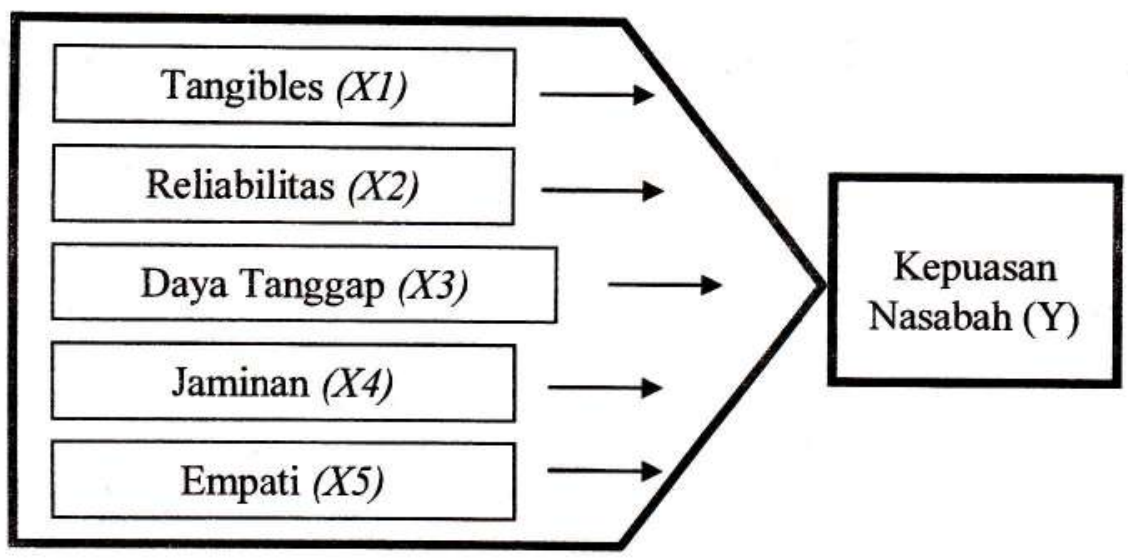

Gambar 2

Model Hipotesis

Keterangan :

$$
=\text { Pengaruh secara parsial }
$$

Pengaruh secara simultan

\section{METODE PENELITIAN}

Penelitian ini dilakukan di wilayah Kota Malang. Waktu pelaksanaan penelitian adalah pada bulan Juni 2014 sampai dengan Desember 2014. Pendekatan penelitian yang digunakan dalam penelitian ini adalah pendekatan eksplanatory, yaitu 


\section{Zaim Mukaffi}

pendekatan yang digunakan peneliti disamping untuk menggali data dari responden, juga untuk menguji hipotesis (Sugiyono, 2005: 16).

Target populasi dalam penelitian ini adalah nasabah perbankan syariah di wilayah Kota Malang. Metode sampel yang digunakan dalam penelitian ini adalah metode systemic quota sampling. Dalam tahap awal dilakukan systemic sampling untuk memilih lokasi penelitian berdasarkan analisis dengan menggunakan kriteria potensi ekonomi, potensi muslim, potensi pembiayaan dan potensi dana pihak ketiga. Penentuan jumlah sampel dari populasi yang diinginkan (Suharjo, 2002)

$$
\mathrm{n}_{0}=\frac{Z^{2} \times p(1-p)}{e^{2}}
$$

Jumlah sampel yang digunakan sebanyak 96 orang. Sedangkan teknik pengumpulan data menggunakan Kuesioner (Angket), Wawancara (Interview) dan Dokumentasi.

Penelitian ini menggunakan skala likert, skala ini mengukur persetujuan atau ketidaksetujuan responden terhadap serangkaian pernyataan yang mengukur suatu objek (Istijanto, 2008 dalam Supriyanto dan Machfudz, 2010: 204), yang nantinya dapat menggunakan scoring atau nilai perbutir, dari jawaban berkisar antara: Sangat tidak setuju dengan nilai 1, Tidak setuju 2, Ragu 3. Setuju, 4. Sangat setuju 5 .

\section{Definisi Operasional Variabel}

Reliabilitas (reliability) Berkaitan dengan kemampuan laboratorium untuk memberikan layanan yang akurat sejak pertama kali tanpa membuat kesalahan apapun dan menyampaikan jasanya sesuai dengan waktu yang disepakati.

Daya tanggap (responssiveness) Berkenaan dengan kesediaan dan kemampuan para pegawai membantu para pelanggan dan merespons permintaan mereka, serta menginformasikan kapan jasa akan diberikan dan kemudian memberikan jasa secara cepat.

Jaminan (assurance) Yakni perilaku pegawai mampu menumbuhkan kepercayaan pelanggan terhadap perusahaan dan perusahaan bisa menciptakan rasa aman bagi para pelanggannya. Jaminan juga berarti bahwa para pegawai selalu bersikap sopan dan menguasai pengetahuan dan ketrampilan yang dibutuhkan untuk menangani setiap pertanyaan atau masalah pelanggan. 
Empati (empathy) Berarti perusahaan memahami masalah pelanggannya dan bertindak demi kepentingan pelanggan, serta memberikan perhatian personal kepada para pelanggan dan memiliki jam operasi yang nyaman.

Bukti fisik (tangibles) Berkenaan dengan daya tarik fasilitas fisik, perlengkapan dan material yang digunakan oleh perusahaan serta penampilan karyawan.

Kepuasan user tingkat perasaan seseorang setelah membandingkan kinerja produk (atau hasil) yang ia rasakan dengan harapannya. Jadi tingkat kepuasan merupakan fungsi dari perbedaan antara kinerja yang dirasakan (perceived performance) dan harapan (expectations)

\section{Uji Validitas dan Reliabilitas}

Ukuran yang menunjukkan sejauh mana instrumen pengukur mampu mengukur apa yang ingin diukur, misalnya menyusun kuesioner maka validitas kuesioner adalah sejauh mana kuesioner ini mampu mengukur obyek yang diteliti (Sulhan, dkk., 2010:5). Untuk mengetahui validitas item, maka penelitian ini menggunakan rumus korelasi product moment Pearson dengan level signifikan 5\% yang dibantu dengan program SPSS 16.00 for windows. Bila nilai signifikansi (sig) hasil korelasi lebih kecil dari $0,05(5 \%)$ maka dinyatakan valid dan sebaliknya dinyatakan tidak valid (artinya butir pertanyaan tersebut gugur).

Sedangkan untuk menentukan reliabel dari tiap item, maka penelitian ini menggunakan metode cronbach alpha yang dibantu dengan program SPSS 16.00 for windows, dimana kuesioner dikatakan reliabel jika nilai cronbach alpha lebih besar dari 0,60.

\section{Uji Asumsi Klasik}

Uji asumsi klasik adalah persyaratan statistik yang harus dipenuhi pada analisis regresi linear berganda yang berbasis Ordinary Least Square(OLS). Jadi analisis regresi yang tidak berdasarkan OLS tidak memerlukan persyaratan asumsi klasik, misalnya regresi logistik atau regresi ordinal. Demikian juga tidak semua uji asumsi klasik harus dilakukan pada analisis regresi linear, misalnya uji multikolinearitas tidak dapat dipergunakan pada analisis regresi linear sederhana dan uji autokorelasi tidak perlu diterapkan pada data cross sectional. Yng terdiri dri Uji Normalitas, Uji Heteroskedastisitas, Uji Multikolinearitas, Uji Autokorelasi dn Uji Linearitas 


\section{Model Analisis Data}

Data dalam penelitian ini penulis menggunakan uji statistik regresi linear berganda. Uji statistik regresi linear berganda digunakan untuk menguji signifikan atau tidaknya hubungan lebih dari dua variabel melalui koefesien regresinya (Iqbal Hasan, 2004)

Persamaan regresi linear berganda sebagai berikut:

$\mathbf{Y}^{\prime}=\mathbf{a}+\mathrm{b}_{1} \mathbf{X}_{1}+\mathrm{b}_{2} \mathbf{X}_{2}+\mathrm{b}_{3} \mathbf{X}_{3}+\mathbf{b}_{4} \mathbf{X}_{4}+\mathrm{b}_{5} \mathbf{X}_{5}+e$

Keterangan:

$Y^{\prime}=$ Kepuasan Nasabah

$X_{5}=$ Empati

$\mathrm{X}_{1}=$ Tangibles

$a=$ Konstanta (nilai $Y^{\prime}$ apabila $X_{1}, X_{2}$ hingga $X_{5}=0$ )

$\mathrm{X}_{2}=$ Reliabilitas $\mathrm{b}=$ Koefisien regresi (nilai peningkatan ataupun penurunan)

$\mathrm{X}_{3}=$ Daya Tanggap nation error

$\mathrm{X}_{4}=$ Jaminan

a. Uji Koefisien Regresi Secara Parsial (Uji t)

Uji ini digunakan untuk mengetahui apakah dalam model regresi variabel independen yang merupakan Tangibles (X1), Reliabilitas (X2), Daya Tanggap(X3), Jaminan (X4), dan Empati (X5) secara parsial berpengaruh signifikan terhadap variabel dependen atau Kepuasan nasabah (Y).

b. Uji Koefisien Regresi Secara Bersama-sama (Uji F)

Uji ini digunakan untuk mengetahui apakah variabel independen atau Tangibles (X1), Reliabilitas (X2), Daya Tanggap (X3), Jaminan (X4), dan Empati (X5) secara bersamasama atau simultan berpengaruh secara signifikan terhadap variabel dependen atau Kepuasan nasabah (Y). Atau untuk mengetahui apakah model regresi dapat digunakan untuk memprediksi variabel dependen atau tidak.

\section{HASIL PENELITIAN DAN PEMBAHASAN}

\section{Data Obyektif Responden}

Data deskripsi identitas responden menggambarkan beberapa kondisi responden. Data deskriptif responden ini memberikan beberapa informasi secara sederhana keadaan responden yang dijadikan obyek penelitian atau dengan kata lain data deskriptif dapat memberikan gambaran tentang keadaan jenis kelamin responden, umur responden, pekerjaan, pendidikan dan pendapatan responden. Kuesioner yang telah diisi sebanyak 96 
Pengaruh Kualitas Pelayanan Perbankan Syariah

responden, kemudian dikompilasi dan diolah menjadi data penelitian.

Karakteristik responden dalam penelitian ini dapat dilihat melalui uraian berikut :

Tabel 1. Karakteristik Responden

\begin{tabular}{|c|c|c|c|}
\hline \multicolumn{2}{|c|}{ Responden } & Jumlah & Persentase \\
\hline \multicolumn{4}{|c|}{ Jenis Kelamin } \\
\hline 1. & Pria & 50 & 52,1 \\
\hline 2. & Wanita & 46 & 47,9 \\
\hline \multicolumn{2}{|r|}{ Total } & 96 & 100 \\
\hline \multicolumn{4}{|c|}{ Umur } \\
\hline 1. & $<20$ tahun & 11 & 11,5 \\
\hline 2. & $20-35$ tahun & 33 & 34,4 \\
\hline 3. & $36-50$ tahun & 40 & 41,7 \\
\hline 4. & $>50$ tahun & 12 & 12,5 \\
\hline \multicolumn{2}{|c|}{ Total } & 96 & 100 \\
\hline \multicolumn{4}{|c|}{ Jenis pekerjaan } \\
\hline 1. & PNS & 10 & 10,4 \\
\hline 2. & Pengusaha & 37 & 38,5 \\
\hline 3. & Karyawan swasta & 35 & 36,5 \\
\hline 4. & Pelajar/mahasiswa & 11 & 11,5 \\
\hline 5. & Ibu rumah tangga & 3 & 3,1 \\
\hline \multicolumn{2}{|r|}{ Total } & 96 & 100 \\
\hline \multicolumn{4}{|c|}{ Pendidikan Terakhir } \\
\hline 1. & SMA & 11 & 11,5 \\
\hline 2. & Sarjana & 66 & 68,6 \\
\hline 3. & Lainnya & 19 & 19,8 \\
\hline \multicolumn{2}{|r|}{ Total } & 96 & 100 \\
\hline \multicolumn{4}{|c|}{ Pendapatan } \\
\hline 1. & $<$ Rp. 1.000 .000 & 11 & 11,5 \\
\hline 2. & $1.000 .000-3.000 .000$ & 41 & 42,7 \\
\hline 3. & $>$ Rp.3.000.000 & 44 & 45,8 \\
\hline \multicolumn{2}{|r|}{ Total } & 96 & 100 \\
\hline
\end{tabular}

Sumber : Data primer yang diolah, 2015

Hasil Analisis dan Pembahasan

Uji Validitas dan Reliabilitas

Tahap awal yang dilakukan setelah kuesioner (angket) diperoleh adalah uji validitas data. Uji validitas dilakukan untuk mengetahui apakah ada pernyataan kuesioner yang harus dibuang atau diganti karena tidak relevan. 
Dalam penelitian ini uji validitas dibantu dengan program SPSS 16.00 for windows, interpretasi koefisien dianggap valid apabila rxy $=0,30(>0,30)$ sehingga butir-butir tersebut dianggap sahih, dan nilai signifikansi (sig) hasil kolerasi lebih kecil dari 0,05 (5\%) maka dinyatakan valid. (Sulhan, dkk., 2010: 6)

Setelah dilakukan uji validitas pada kuesioner (angket) yang diperoleh, kemudian dilakukan uji reliabilitas untuk mengetahui tingkat kemantapan atau konsistenitas suatu alat ukur. Reliabilitas memberikan kesesuaian antara hasil dengan pengukuran. Suatu instrument yang reliable mengandung arti bahwa instrument tersebut cukup baik sehingga mampu mengungkap data yang akurat dan dipercaya.

Dalam Penelitian ini uji reliabilitas dibantu dengan program SPSS 16.00 for windows dilakukan dengan menggunakan rumus Alpha-Cronbach guna mengetahui apakah hasil pengukuran data yang diperoleh memenuhi syarat reliabilitas. Instrumen kuesioner (angket) dapat dikatakan reliabel bila memiliki koefisien alpha lebih besar dari 0,6 .

Adapun hasil uji validitas dan uji reliabilitas dalam penelitian ini dapat dilihat pada tabel 2 dibawah ini:

Tabel 2 Uji Validitas dan Reliabilitas

\begin{tabular}{|c|c|c|c|c|c|c|}
\hline \multirow[t]{2}{*}{ Variabel } & \multirow[t]{2}{*}{ Item } & \multicolumn{2}{|c|}{ Validitas } & \multirow{2}{*}{$\begin{array}{c}\text { Ketera } \\
\text { ngan }\end{array}$} & \multirow{2}{*}{$\begin{array}{l}\text { Cronb } \\
\text { ach's } \\
\text { Alpha }\end{array}$} & \multirow[t]{2}{*}{ Keterangan } \\
\hline & & $\mathbf{R}$ & Sig & & & \\
\hline \multirow{3}{*}{$\begin{array}{l}\text { Tangibles } \\
\text { (X1) }\end{array}$} & $\mathrm{X} 1.1$ & 0,746 & 0 & Valid & 0,761 & Reliabel \\
\hline & $\mathrm{X} 1.2$ & 0,867 & 0 & Valid & 0,761 & Reliabel \\
\hline & $\mathrm{X} 1.3$ & 0,846 & 0 & Valid & 0,761 & Reliabel \\
\hline \multirow{2}{*}{$\begin{array}{c}\text { Reliabilitas } \\
\text { (X2) }\end{array}$} & X.2.1 & 0,781 & 0 & Valid & 0,784 & Reliabel \\
\hline & X.2.2 & 0,793 & 0 & Valid & 0,784 & Reliabel \\
\hline \multirow{2}{*}{$\begin{array}{c}\text { Daya } \\
\text { Tanggap } \\
\text { (X3) }\end{array}$} & $\mathrm{X} 3.1$ & 0,925 & 0 & Valid & 0,815 & Reliabel \\
\hline & $\mathrm{X} 3.2$ & 0,913 & 0 & Valid & 0,815 & Reliabel \\
\hline \multirow{2}{*}{$\begin{array}{l}\text { Jaminan } \\
\text { (X4) }\end{array}$} & $\mathrm{X} 4.1$ & 0,97 & 0 & Valid & 0,935 & Reliabel \\
\hline & $\mathrm{X} 4.2$ & 0,986 & 0 & Valid & 0,935 & Reliabel \\
\hline \multirow{2}{*}{$\begin{array}{c}\text { Empati } \\
\text { (X5) }\end{array}$} & $\mathrm{X} 5.1$ & 0,979 & 0 & Valid & 0,959 & Reliabel \\
\hline & $\mathrm{X} 5.2$ & 0,81 & 0 & Valid & 0,959 & Reliabel \\
\hline \multirow{2}{*}{$\begin{array}{c}\text { Kepuasan } \\
\text { Nasabah }\end{array}$} & $\mathrm{Y1}$ & 0,733 & 0 & Valid & 0,911 & Reliabel \\
\hline & $\mathrm{Y} 2$ & 0,779 & 0 & Valid & 0,911 & Reliabel \\
\hline
\end{tabular}

El-Dinar, Vol. 4, No. 2, Juli 2016 
Pengaruh Kualitas Pelayanan Perbankan Syariah

\begin{tabular}{|c|c|c|c|c|c|c|}
\hline (Y) & Y3 & 0,871 & 0 & Valid & 0,911 & Reliabel \\
\cline { 2 - 7 } & Y4 & 0,715 & 0 & Valid & 0,911 & Reliabel \\
\cline { 2 - 7 } & Y5 & 0,606 & 0 & Valid & 0,911 & Reliabel \\
\cline { 2 - 7 } & Y6 & 0,832 & 0 & Valid & 0,911 & Reliabel \\
\hline & Y7 & 0,643 & 0 & Valid & 0,911 & Reliabel \\
\cline { 2 - 7 } & Y8 & 0,882 & 0 & Valid & 0,911 & Reliabel \\
\cline { 2 - 7 } & Y9 & 0,818 & 0 & Valid & 0,911 & Reliabel \\
\hline
\end{tabular}

Sumber: Data Primer yang diolah (tahun 2015)

\section{Hasil Uji Asumsi Klasik}

\section{a. Hasil Uji Multikolinieritas}

Uji multikolinieritas dilakukan untuk mengetahui apakah model regresi berganda yang diajukan ditemukan kolerasi yang kuat antara variabel-variabel independen. Jika terjadi kolerasi yang kuat, maka terdapat masalah multikolinieritas yang harus diatasi. Sebaliknya bebas multikolinieritas apabila ditemukan kolerasi yang lemah antara variabel-variabel independen.

Untuk mengetahui terjadi atau tidaknya multikolinieritas maka dilihat melalui tolerance value yang mendekati angka 1 atau Variance Inflation Factor (VIF) antara 1 samapai 10 maka tidak terdapat masalah multikolinieritas. Setelah dilakukan pengujian dengan SPSS 16.00 for windows, dihasilkan nilai VIF dan tolerance yang dapat dilihat pada tabel 3 sebagai berikut :

Tabel 3

Hasil Uji Multikolinearitas

\begin{tabular}{|c|c|c|c|}
\hline \multirow{2}{*}{ Model } & \multicolumn{2}{|c|}{ Collinearity statistic } & \multirow{2}{*}{ Keterangan } \\
\cline { 2 - 3 } & Tollerance & VIF & \\
\hline X1 & 0,889 & 1,125 & Bebas Multikolinearitas \\
\hline X2 & 0,639 & 1,566 & Bebas Multikolinearitas \\
\hline X3 & 0,816 & 1,226 & Bebas Multikolinearitas \\
\hline X4 & 0,46 & 2,173 & Bebas Multikolinearitas \\
\hline X5 & 0,725 & 1,38 & Bebas Multikolinearitas \\
\hline
\end{tabular}

Sumber: Data Primer yang diolah (tahun 2015)

Dari tabel di atas dapat dilihat bahwa setiap variabel independen memiliki nilai Variance Inflation Factor (VIF) berada antara 1 sampai 10, demikian juga hasil tolerance value mendekati 
1. Hal ini berarti bahwa antar variabel independen tidak memiliki hubungan yang kuat atau kolerasi lemah dan signifikan, maka model regresi berganda dalam penelitian ini tidak terdapat masalah multikolinieritas.

b. Hasil Uji Autokolerasi

Uji autokolerasi dilakukan untuk mengetahui apakan model regresi berganda ditemukan kolerasi antara kesalahan pengganggu pada periode $t$ dengan kesalahan penganggu pada periode $t-1$ (sebelumnya). Jika terjadi kolerasi, maka dinamakan ada problem autokolerasi.

Untuk mengetahui terjadi atau tidaknya antokolerasi maka dilihat melalui Durbin-Watson yaitu du $<\mathrm{dw}<4$-du atau nilai Durbin-Watson mendekati angka 2, maka asumsi tidak terjadi autokolerasi terpenuhi. Setelakan dilakukan uji autokolerasi dengan program SPSS 16.00 for windows, dihasilkan nilai DurbinWatson yang dapat dilihat pada tabel 4 sebagai berikut :

Tabel 4 Hasil Uji Autokorelasi

\begin{tabular}{|l|c|r|r|r|r|}
\hline Model & R & R Square & $\begin{array}{c}\text { Adjusted R } \\
\text { Square }\end{array}$ & $\begin{array}{c}\text { Std. Error of the } \\
\text { Estimate }\end{array}$ & Durbin-Watson \\
\hline 1 & $.661^{\mathrm{a}}$ & .437 & .319 & .55165 & 1.223 \\
\hline
\end{tabular}

a. Predictors: (Constant), Empati, Daya Tanggap, Jaminan, Reliabilitas, Tangibles

b. Dependent Variable: Kepuasan Pengguna

Sumber: Data Primer yang diolah (tahun 2015)

Dari tabel di atas dapat dilihat bahwa nilai DW $=1,223$, mendekati angka 2 berarti hasil pada penelitian tidak terjadi autokorelasi.

c. Hasil Uji Heteroskedastisitas

Uji heteroskedastisitas dilakukan untuk mengetahui apakah model regresi terjadi ketidaksamaan varians dari residual antara satu pengamat dengan pengamat yang lain.

Untuk mengetahui terjadi atau tidaknya heteroskedastisitas dapat dilihat dengan menggunakan uji koefisien korelasi Rank Spearman yaitu mengkolerasikan antara absolut residual hasil regresi dengan semua variabel bebas; bila signifikansi hasil korelasi lebih kecil dari 0,05 (5\%) maka persamaan regresi mengandung heteroskedastisitas dan sebaliknya tidak mengandung heteroskedastisitas apabila signifikansi hasil korelasi lebih besar dari $0,05(5 \%)$. Setelah dilakukan uji heteroskedastisitas dengan menggunakan program SPSS 16.00 for windows, dihasilkan nilai 
Pengaruh Kualitas Pelayanan Perbankan Syariah

signifikansi hasil korelasi dapat dilihat pada tabel 5 sebagai berikut:

Tabel 5 Hasil Uji Heteroskedastisitas

\begin{tabular}{|c|c|c|c|}
\hline Variabel & $\mathbf{R}$ & Sig & Keterangan \\
\hline Tangibles (X1) & 0,099 & 0,502 & Bebas Heteroskedastisitas \\
\hline Reliabilitas (X2) & 0,104 & 0,481 & Bebas Heteroskedastisitas \\
\hline Daya Tanggap (X3) & 0,026 & 0,858 & Bebas Heteroskedastisitas \\
\hline Jaminan (X4) & 0,019 & 0,899 & Bebas Heteroskedastisitas \\
\hline Empati (X5) & 0,074 & 0,619 & Bebas Heteroskedastisitas \\
\hline
\end{tabular}

Sumber: Data Primer yang_diolah (tahun 2015)

Dari tabel di atas dapat dilihat nilai signifikan hasil kolerasi variabel Tangibles $(x 1)=0,502$, variabel Reliabilitas $(x 2)=0,481$, variabel Daya Tanggap $(x 3)=0,585$, variabel Jaminan $(x 4)=0,899$, variabel Empati $(x 5)=0,619$ lebih besar dari 0,05 (5\%). Maka model regresi dalam penelitian ini tidak ada masalah heteroskedastisitas.

d. Hasil Uji Normalitas

Uji normalitas dilakukan untuk mengetahui apakah model regresi yang diteliti berdistribusi normal atau tidak. Untuk mengetahui normal atau tidaknya model regresi berganda dapat dengan menggunakan uji Kolmogorov-Smirnov, Jika nilai signifikansi dari hasil uji Kolmogrorov-Smirnov > 0,05 maka asumsi normalitas terpenuhi.

Setelah dilakukan uji normalitas dengan menggunakan program SPSS 16.00 for windows, dihasilkan nilai signifikansi dari hasil uji Kolmogorov-Smirnov yang dilihat pada tabel sebagai berikut :

Tabel 6 Hasil Uji Normalitas

One-Sample Kolmogorov-Smirnov Test

\begin{tabular}{|ll|r|}
\hline & & Unstandardized Residual \\
\hline Normal Parameters & \\
& & 48 \\
& Mean & .0000000 \\
Most Extreme Differences & Std. Deviation & 5.46113572 \\
& Absolute & .170 \\
& Positive & .142 \\
& Negative & -.170 \\
Kolmogorov-Smirnov Z & & 1.178 \\
Asymp. Sig. (2-tailed) & & .124 \\
\hline
\end{tabular}

Sumber: Data Primer yang diolah (tahun 2015) 
Dari tabel di atas dapat dilihat nilai signifikansi sebesar 0.124 $>0,05$, maka asumsi normalitas terpenuhi.

\section{Hasil Uji Regresi Berganda}

Berdasarkan data penelitian yang telah dkumpulkan melalui kuesioner (angket), baik untuk variabel dependen yaitu Kepuasan nasabah $(\mathrm{Y})$ maupun variabel independen X1, X2, X3, X4 dan X5 yang meliputi Tangibles, Reliabilitas, Daya Tanggap, Jaminan, dan Empati yang diolah dengan menggunakan regresi linear berganda, dilakukan beberapa tahapan untuk mencari hubungan antara variabel independen dengan variabel dependen yang dibantu dengan Program SPSS 16.00 for windows, maka diperoleh hasil perhitungan regresi linear berganda yang dapat dilihat pada tabel 7 sebagai berikut :

Tabel 7 Hasil Uji Regresi Berganda

\begin{tabular}{|l|c|c|c|c|}
\hline \multicolumn{1}{|c|}{ Variabel } & $\begin{array}{c}\text { Unstandardized } \\
\text { beta }\end{array}$ & $\mathbf{T}$ & Sig & $\begin{array}{c}\text { Keteranga } \\
\mathbf{n}\end{array}$ \\
\hline (constant) & 0,458 & 5,134 & 0.000 & \\
\hline Tangibles (X1) & -.004 & -.266 & .791 & $\begin{array}{c}\text { Tidak } \\
\text { Signifikan }\end{array}$ \\
\hline Reliabilitas (X2) & 0,072 & 5.445 & .000 & Signifikan \\
\hline Daya Tanggap (X3) & .061 & 3.795 & .000 & Signifikan \\
\hline Jaminan (X4) & .060 & 3.744 & .001 & Signifikan \\
\hline Empati (X5) & .151 & 2.595 & .013 & Signifikan \\
\hline $\mathbf{R}$ & & $=\mathbf{0 . 6 6 1}$ & & \\
R Square & $=\mathbf{0 , 4 3 7}$ & & \\
Adjusted R Square & & $=\mathbf{0 , 3 1 9}$ & & \\
F hitung & $=\mathbf{3 . 7 2 2}$ \\
Sign. F & $=\mathbf{0 , 0 1 2}$ \\
$\mathbf{a}$ & $=\mathbf{0 , 1}$ \\
\hline
\end{tabular}

Sumber: Data Primer yang diolah (tahun 2014)

Variabel tergantung pada regresi ini adalah $\mathrm{Y}$ sedangkan variabel bebasnya adalah $\mathrm{X} 1, \mathrm{X} 2, \mathrm{X} 3, \mathrm{X} 4$ dan $\mathrm{X} 5$ Model regresi berdasarkan hasil analisis di atas adalah : $\mathrm{Y}=0.661^{\mathrm{a}}+-0.004+0,072+0.061+0.060+0.151+\mathrm{e}$ 
Tampak pada persamaan tersebut menunjukkan angka yang tidak signifikan pada variabel X1 (Tangibles), dan X2 (Reliabilitas), X3 (Daya Tanggap), X4 (Jaminan) dan X5 (Empati) menunjukkan angka yang signifikan. Adapun interpretasi dari persamaan tersebut adalah :

1. $\mathrm{bo}=0,458$

Nilai konstan ini menunjukkan bahwa apabila tidak ada variabel Tangibles (X1), Reliabilitas (X2), Daya Tanggap (X3), Jaminan (X4), Empati (X5), maka Kepuasan nasabah akan bertambah sebesar 0,458. Dalam arti Kepuasan nasabah akan bertambah sebesar 0,458 sebelum atau tanpa adanya variable Tangibles, Reliabilitas, Daya Tanggap, Jaminan, dan Empati, (X1, $\mathrm{X} 2, \mathrm{X} 3, \mathrm{X} 4, \mathrm{X} 5=0$ ).

2. $b_{1}=-0,004$

Nilai parameter atau koefisien regresi b2 ini menunjukkan bahwa setiap variable pada indikator Tangibles bertambah $1 \mathrm{kali}$, maka Kepuasan nasabah akan berkurang sebesar -0,004 kali atau dengan kata lain setiap penambahan Kepuasan nasabah dibutuhkan pengurangan variabel pada indikator Tangibles sebesar $-0,004$ dengan asumsi variabel bebas yang lain tetap $(X 2$, $\mathrm{X} 3, \mathrm{X} 4, \mathrm{X} 5=0$ ).

3. $b_{2}=0,072$

Nilai parameter atau koefisien regresi b2 ini menunjukkan bahwa setiap variable pada indikator Reliabilitas bertambah 1 kali, maka Kepuasan nasabah akan bertambah sebesar 0,072 kali atau dengan kata lain setiap penambahan Kepuasan nasabah dibutuhkan variabel pada indikator Reliabilitas sebesar 0,072 dengan asumsi variabel bebas yang lain tetap $(\mathrm{X} 1, \mathrm{X} 3, \mathrm{X} 4, \mathrm{X} 5=0)$.

4. $b_{3}=0.061$

Nilai parameter atau koefisien regresi $b_{2}$ ini menunjukkan bahwa setiap variable pada indikator Daya Tanggap bertambah 1 kali, maka Kepuasan nasabah akan bertambah sebesar 0,061 kali atau dengan kata lain setiap penambahan Kepuasan nasabah dibutuhkan variable indikator Daya Tanggap sebesar 0,061 dengan asumsi variabel bebas yang lain tetap $(\mathrm{X} 1, \mathrm{X} 2, \mathrm{X} 4, \mathrm{X} 5=0)$.

5. $\mathrm{b}_{4}=0,060$

Nilai parameter atau koefisien regresi $b_{2}$ ini menunjukkan bahwa setiap variabel pada indikator Jaminan bertambah 1 kali, maka Kepuasan nasabah akan bertambah sebesar 0,060 kali atau dengan kata lain setiap penambahan Kepuasan nasabah 
dibutuhkan variable pada indikator Jaminan sebesar 0,060 dengan asumsi variabel bebas yang lain tetap $(\mathrm{X} 1, \mathrm{X} 2, \mathrm{X} 3, \mathrm{X} 5=0)$.

6. $b_{5}=0.151$

Nilai parameter atau koefisien regresi $b_{2}$ ini menunjukkan bahwa setiap variable pada indikator Empati bertambah 1 kali, maka Kepuasan nasabah akan bertambah sebesar 0,151 kali atau dengan kata lain setiap penambahan Kepuasan nasabah dibutuhkan variable pada indikator Empati sebesar 0,151 dengan asumsi variabel bebas yang lain totap $(\mathrm{X} 1, \mathrm{X} 2, \mathrm{X} 3, \mathrm{X} 4=0)$.

\section{Pengujian Hipotesis}

Sesuai dengan kaidah dalam melakukan analisis regresi berganda, bahwa suatu persamaan regresi harus memiliki data yang terdistribusi secara normal, bebas autokolerasi, bebas heteroskedastisitas, dan bebas multikolinieritas agar dapat memperoleh persamaan regresi yang baik dan tidak bias. Dari hasil uji distribusi normal, uji autokolerasi, uji heteroskedastisitas, dan uji multikolinieritas yang telah dilakukan di atas, makadapat diketahui bahwa data yang digunakan dalam penelitian ini telah memenuhi persyaratan untuk melakukan analisis regresi berganda dengan baik.

Hipotesis dalam penelitian ini diuji dengan menggunakan multiple regression. Tujuannya adalah untuk mengetahui apakah variabel variabel X1 (Tangibles), dan X2 (Reliabilitas), X3 (Daya Tanggap), X4 (Jaminan) dan X5 (Empati) berpengaruh dalam Kepuasan nasabah. Adupun hasil uji $\mathrm{R}^{2}, \mathrm{~F}$ dan $\mathrm{t}$ adalah sebagai berikut :

\section{Koefisien determinasi $\left(\mathrm{R}^{2}\right)$}

Koefisien determinasi $\left(R^{2}\right)$ digunakan untuk mengukur seberapa jauh kemampuan model dalam menerangkan variasi variabel dependen. Nilai koefisien determinasi adalah di antara nol dan satu. Nilai Koefisien determinasi $\left(R^{2}\right)$ yang kecil berarti kemampuan variabel-variabel independen dalam menjelaskan variasi variabel dependen amat terbatas. Nilai yang mendekati satu berarti variabel-variabel independen memberikan hampir semua informasi yang dibutuhkan untuk memprediksi variasi variabel dependen. Adapun hasil perhitungan koefisien determinasi $\left(R^{2}\right)$ yang dibantu dengan program SPSS 16.00 for windows dapat dilihat pada tabel 8 sebagai berikut: 
Pengaruh Kualitas Pelayanan Perbankan Syariah

Tabel 8 Koefisien Determinasi

\begin{tabular}{|c|c|c|c|c|}
\hline Model & $\mathbf{R}$ & R Square & $\begin{array}{c}\text { Adjusted R } \\
\text { Square }\end{array}$ & $\begin{array}{c}\text { Std. Error of the } \\
\text { Estimate }\end{array}$ \\
\hline 1 & $.661 \mathrm{a}$ & .319 & .437 & .55165 \\
\hline
\end{tabular}

Dari tabel 8 di atas dapat dilihat, bahwa koefisien determinasi yang menunjukkan modal variabel bebas X1 (Tangibles), dan X2 (Reliabilitas), X3 (Daya Tanggap), X4 (Jaminan) dan X5 (Empati) dalam menjelaskan variabel dependen Kepuasan nasabah yaitu sebesar 0,437. Hal ini berarti variabel independen (variabel X1 (Tangibles), dan X2 (Reliabilitas), X3 (Daya Tanggap), X4 (Jaminan) dan X5 (Empati)) mampu menjelaskan variabel dependen Kepuasan nasabah sebesar $43.7 \%$ dan sisanya $56.3 \%$ dipengaruhi oleh faktor lain.

2. Uji Simultan (uji F)

Uji simultan merupakan alat uji statistik secara simultan untuk mengetahui pengaruh variabel bebas $\mathrm{X} 1$ (Tangibles), dan $\mathrm{X} 2$ (Reliabilitas), X3 (Daya Tanggap), X4 (Jaminan) dan X5 (Empati) terhadap variabel terikat Kepuasan nasabah secara bersama-sama. Adapun Hasil uji simultan (uji F) yang dibantu dengan program SPSS 16.00 for windows dapat dilihat pada tabel 9 sebagai berikut :

Tabel 9 Hasil Uji Simultan (Uji F)

\begin{tabular}{|c|c|c|c|c|c|c|}
\hline \multicolumn{2}{|c|}{ Model } & Sum of Squares & df & Mean Square & $\mathrm{F}$ & Sig. \\
\hline \multirow[t]{3}{*}{1} & Regression & 5.663 & 5 & 1.133 & 3.722 & $.012^{\mathrm{a}}$ \\
\hline & Residual & 7.304 & 24 & .304 & & \\
\hline & Total & 12.967 & 29 & & & \\
\hline
\end{tabular}

a. Predictors: (Constant), Empati, Daya Tanggap, Jaminan, Reliabilitas, Tangibles

b. Dependent Variable: Kepuasan Pengguna

Sumber: Data Primer yang diolah (tahun 2015)

F hitung $(3,722)>\mathrm{F}$ tabel $(2,437)$ dan probabilitas $(0,012)<$ 0,05, Maka Ho ditolak dan Ha diterima, jadi variabel Tangibles, Reliabilitas, Daya Tanggap, Jaminan, dan Empati secara simultan (bersama-sama) berpengaruh terhadap Kepuasan nasabah.

3. Uji Parsial (uji t)

Uji parsial merupakan alat uji statistik secara parsial untuk mengetahui pengaruh variabel bebas Tangibles, Reliabilitas, Daya 
Tanggap, Jaminan, dan Empati secara simultan terhadap variabel terikat Kepuasan nasabah secara parsial. Adapun Hasil uji parsial (uji t) yang dibantu dengan program SPSS 16.00 for windows dapat dilihat pada tabel 10 sebagai berikut :

Tabel 10 Uji-t

\begin{tabular}{|c|c|c|c|c|c|}
\hline & \multicolumn{2}{|c|}{ Unstandardized Coefficients } & \multirow{2}{*}{$\begin{array}{l}\begin{array}{c}\text { Standardized } \\
\text { coeficients }\end{array} \\
\text { Beta }\end{array}$} & \multirow[b]{2}{*}{$\mathrm{t}$} & \multirow[b]{2}{*}{ Sig. } \\
\hline & B & d. Error & & & \\
\hline 1 (Constant) & 3.815 & 2.299 & & 1.660 & .110 \\
\hline Tangibles & .153 & .124 & .232 & 1.232 & .230 \\
\hline Reliabilitas & .463 & .135 & .601 & 3.428 & .002 \\
\hline Daya Tanggap & -.050 & .161 & -.052 & -.309 & .760 \\
\hline Jaminan & .119 & .216 & .097 & .549 & .588 \\
\hline Empati & -.103 & .154 & -.117 & -.667 & .511 \\
\hline
\end{tabular}

Sumber: Data Primer yang diolah (tahun 2015)

Untuk variabel Tangibles (X1) koefisien regresi sebesar $0.153, \mathrm{~T}$ hitung (1.232) > T tabel (2.571) dan probabilitas $(0,230)>0,05$, Maka Ho diterima dan Ha ditolak, jadi variabel Tangibles (X1)tidak berpengaruh terhadap Kepuasan nasabah. Untuk variabel Reliabilitas (X2) koefisien regresi sebesar .463, $\mathrm{t}$ hitung (3.428) $>\mathrm{t}$ tabel (2.571) probabilitas $(.002)<0,05$, Maka Ho ditolak dan Ha diterima, jadi variabel Reliabilitas berpengaruh terhadap Kepuasan nasabah.

Untuk variabel Daya Tanggap (X3) koefisien regresi sebesar -050 , $\mathrm{t}$ hitung $(-.390)>\mathrm{t}$ tabel $(2.571)$ probabilitas $(.760)>0,05$, Maka Ho diterima dan Ha ditolak, jadi Daya Tanggap tidak berpengaruh terhadap Kepuasan nasabah. Untuk Jaminan (X4) koefisien regresi sebesar' 0.119 , $t$ hitung $(0.549)>t$ tabel $(2.571)$ dan probabilitas $(0.558)<(0,05)$, Maka Ho diterima dan Ha ditolak, jadi variabel Jaminan tidak berpengaruh terhadap Kepuasan nasabah. Untuk variabel Empati (X5) koefisien regresi sebesar $-0.103, \mathrm{t}$ hitung $(-0.667)>t$ tabel $(2.571)$ dan probabilitas $(0.511)<(0,05)$, Maka Ho diterima dan Ha ditolak, jadi variabel Empati tidak berpengaruh terhadap kepuasan nasabah. 


\section{Pengaruh Kualitas Pelayanan Perbankan Syariah}

4. Uji Variabel Dominan

Uji variabel dominan digunakan untuk melihat variabel mana yang memiliki kontribusi pengaruh tertinggi dan untuk melihat variabel yang memiliki kontribusi pengaruh yang kurang. Uji dominan ini dapat digunakan sebagai bahan pertimbangan dalam upaya perbaikan kepuasan nasabah di perbankan syariah kota Malang. Hasil dari pengujian variabel dominan akan dijelaskan sebagai berikut:

Tabel: 11 Uji Variabel Dominan

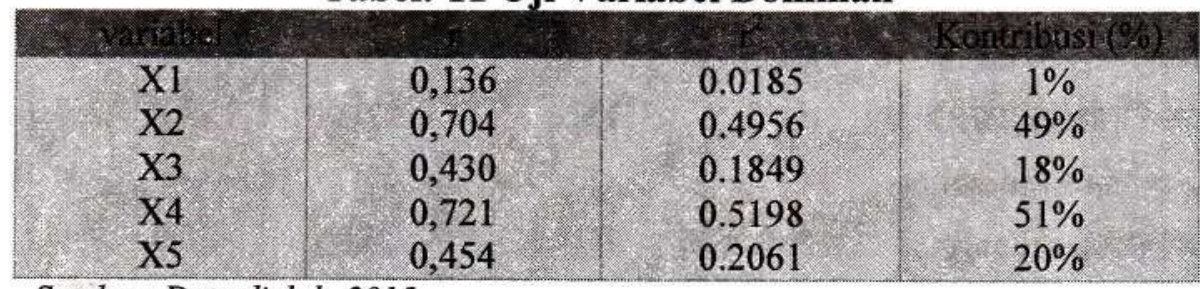

Sumber: Data diolah, 2015.

Berdasarkan tabel 11 dapat ditarik kesimpulan bahwa variabel yang paling dominan yang mempengaruhi Kepuasan nasabah pada perbankan syariah kota Malang adalah variabel Jaminan $\left(X_{4}\right)$ dengan kontribusi $51 \%$. Dilihat dari tabel diatas dapat membuktikan bahwa Jaminan $\left(\mathrm{X}_{4}\right)$ pada perbankan syariah kota Malang dapat memberikan pengaruh terhadap kepuasan nasabah, Sedangkan variabel yang hasil kontribusinya paling rendah adalah pada variabel Tangibles $\left(X_{1}\right)$ dengan kontribusi $1 \%$ hal ini karena memang Tangibles tidak berpengaruh signifikan terhadap Kepuasan nasabah pada perbankan syariah kota Malang.

\section{Pembahasan Data Hasil Penelitian}

Berdasarkan hasil penelitian di atas terkait dengan judul, permasalahan, tujuan dan hipotesis penelitian, maka dalam penelitian ini ada beberapa hal yang dapat dijelaskan yaitu sebagai berikut :

\section{Analisis Pengaruh Tangibles terhadap Kepuasan nasabah.}

Dari hasil penelitian ini secara parsial menunjukkan bahwa Untuk variabel Tangibles (X1) koefisien regresi sebesar 0.153 ,T hitung (1.232) $>\mathrm{T}$ tabel $(2.571)$ dan probabilitas $(0,230)>0,05$, Maka Ho diterima dan Ha ditolak, jadi variabel Tangibles (X1)tidak berpengaruh terhadap Kepuasan nasabah. 
Analisis Pengaruh Reliabilitas terhadap Kepuasan nasabah.

Untuk variabel Reliabilitas (X2) koefisien regresi sebesar 0.463 , $\mathrm{t}$ hitung $(3.428)>\mathrm{t}$ tabel $(2.571)$ probabilitas $(.002)<0,05$, Maka Ho ditolak dan $\mathrm{Ha}$ diterima, jadi variabel Reliabilitas berpengaruh terhadap Kepuasan nasabah.

Analisis Pengaruh Daya Tanggap terhadap Kepuasan nasabah.

Untuk variabel Daya Tanggap (X3) koefisien regresi sebesar -050 , t hitung $(-.390)>\mathrm{t}$ tabel $(2.571)$ probabilitas $(.760)>0,05$, Maka Ho diterima dan Ha ditolak, jadi Daya Tanggap tidak berpengaruh terhadap Kepuasan nasabah

\section{Analisis Pengaruh Jaminan terhadap Kepuasan nasabah.}

Untuk Jaminan $(X 4)$ koefisien regresi sebesar 0.119, t hitung $(0.549)>t$ tabel $(2.571)$ dan probabilitas $(0.558)<(0,05)$, Maka Ho diterima dan Ha ditolak, jadi variabel Jaminan tidak berpengaruh terhadap Kepuasan nasabah.

Analisis Pengaruh Empati terhadap Kepuasan nasabah.

Untuk variabel Empati (X5) koefisien regresi sebesar -0.103 , $\mathrm{t}$ hitung $(-0.667)>\mathrm{t}$ tabel $(2.571)$ dan probabilitas $(0.511)<(0,05)$, Maka Ho diterima dan Ha ditolak, jadi variabel Empati tidak berpengaruh terhadap kepuasan nasabah.

Analisis Pengaruh Tangibles, Reliabilitas, Daya Tanggap, Jaminan, dan Empati Secara Simultan terhadap Kepuasan nasabah.

F hitung $(3,722)>$ F tabel $(2,437)$ dan probabilitas $(0,012)<$ 0,05, Maka Ho ditolak dan Ha diterima, jadi variabel Tangibles, Reliabilitas, Daya Tanggap, Jaminan, dan Empati secara simultan (bersama-sama) berpengaruh terhadap Kepuasan nasabah .

\section{KESIMPULAN DAN SARAN}

\section{Kesimpulan}

Berdasarkan hasil analisis, maka hasil dari penelitian ini dapat disimpulkan sebagai berikut:

1. Secara simultan variabel Tangibles, Reliabilitas, Daya Tanggap, Jaminan, dan Empati secara simultan (bersama-sama) berpengaruh terhadap Kepuasan nasabah. 


\section{Pengaruh Kualitas Pelayanan Perbankan Syariah}

2. Untuk variabel Tangibles, Daya Tanggap, Jaminan dan Empati berpengaruh tidak terhadap Kepuasan nasabah. sedangkan variabel Reliabilitas berpengaruh terhadap Kepuasan nasabah.

3. Variable yang dominan yang mempengaruhi Kepuasan nasabah pada perbankan syariah di kota Malang adalah variabel Jaminan $\left(X_{4}\right)$ dengan kontribusi $51 \%$.

\section{Saran}

Sebagai industri jasa, perbankan syariah harus selalu meningkatkan kualitas layanan khususnya terkait dengan informasi/ sosialisasi yang lebih intensif terhadap nasabah. Disamping itu, terkait juga dengan layanan lainnya seperti ketersediaan ATM dll. Maka perlu diperluas/ditambah lagi agar dapat memudahkan nasabah.

\section{DAFTAR PUSTAKA}

A. Rofiq, "Pengaruh Dimensi Kepercayaan (Trust) terhadap Partisipasi Pelanggan e-Commerce. Studi pada Pelanggan e-Commerce di Indonesia," Tesis, tidak dipublikasikan, Program Studi Manajemen FE-UB, 2007

Andrian Payne 2000, The Essence of Services Marketing, Penerrbit Andi, Jogjakarta.

Arindita, Aloysius Reza \& Sulistyaningtyas, Ike Devi (2011).

Pengaruh Kualitas Pelayanan Terhadap Citra Perusahaan

Di Olimart Pt. Wina Wira Usaha. Jurnal UWM.

Bitner, M. J. and Hubbert, A. R. Encounter Satisfaction versus Overall Satisfaction versus Quality, in Service Quality: New Directions in Theory and Practice, R. T. Rust \& R.L. Oliver [Eds.]. Thousand Oaks, CA: Sage Publications, 72-94, 1994. Cahyani, Putri Dwi. 2011. Tingkat Kepuasan Nasabah terhadap Kualitas Kinerja Perbankan Syariah (Studi pada BMI, BNI Syariah, BTN Syariah dan BPD Syariah DIY Cabang Yokyakarta. Tesis. Unpublished.

Gill, Amarjit S.; Flaschner, Alan B.; Shachar, Mickey. "Factors that Affect The Trust Of Business Clients in Their Banks". International Journal of Bank Marketing, 24 (6): 384 - 405, 2006

Hasan Ikbal, 2004 Analisi Data Penelitian Dengan Statistik. Jakarta:

Penerbit PT Bumi Aksara.

Johnson Michael D., Gustafsson Anders, Andreassen T.W., Lervick L., Cha J., The Evolution and Future of National Customer 
Satisfaction Index Models. Journal of Economic Psychology. 22: $217-245,2000$

Koetin, E.A. 2002. Analisis Pasar Modal. Jakarta: Pustaka Sinar Harapan.

Kohli A. K., and Jaworski B. J. "Market Orientation: The Construct, Research Propositions, and Managerial Implications". Journal of Marketing, 54 (2): 1-18, 1990

Kotler, Philip. 2000. Manajemen P'rasaran : Analisis, Perencanaan, Implementasi dan Pengendaiian di Indonesia. Alih Bahasa oleh Anitawati. Jakarta : Penerbit Salemba

Philip Kotler. 2005. Manajemen Pemasaran, Jakarta: PT. Indeks Kelompok Gramedia.

Munir, A.A.S. 1991. Manajemen Pelayanan Umum di Indonesia, Gramedia. Jakarta. Pawitra, Teddy. 1993. Pemasaran: Dimensi Falsafah, Disiplin, dan Keahlian, Sekolah Tinggi Manajemen Prasetya Mulya. Jakarta.

Satriyani, Evi Okatviani. 2012. Pengaruh Kualitas Layanan, Kepuasan Nasabah Dan Citra Bank Terhadap Loyalitas Nasabah Bank Muamalat Di Surabaya. Urnal Ekonomi. STIE Perbanas Surabaya.

Sulhan, Muhammad, dkk. 2010. Panduan Praktis Analisis SPSS

Untuk Manajemen (keuangan, SDM \& Pemesaran). Malang:

CLICT FE UIN Malang.

Sugiyono. 2003. Metode Penelitian Bisnis. Bandung: Pusat Bahasa

Depdiknas 2005. Statistik untuk Penelitian, Cetakan ke delapan.

Bandung: CV. Alfabeta

Soeratno \& Lincolin Rasyad, Metodologi Penelitian, Edisi Revisi, (Yogyakarta: UPP AMP YKPN, 1993).

Soenarmi. 2011. Pengaruh Kualitas Layanan Terhadap kepuasan dan Loyalitas Nasabah Pada Perbankan Syariah di Kota Malang. Jurnal UWM

Tjiptono, Fandy, 2006. Strategi Pemasaran, Penerbit Andi: Yogyakarta.

Tjiptono dan chandra. (2005). Service Quality and Satisfaction. Edisi

2. Andi, Yogyakarta.

Umar, Sekaran, 2006,Metode Riset Bisnis, PT. Gramedia Pustaka Utama, Jakarta

Undang-Undang Nomor 21 Tahun 2008 tentang Perbankan Syariah. 
Pengaruh Kualitas Pelayanan Perbankan Syariah

Usman, Rachmadi. 2002. Aspek-Aspek Hukum Perbankan Islam di Indonesia, Bandung: PT. Citra Aditya Bakti.

Widyaratna Danny, Theresia, Filicia Chandra, 2001. Analisis

Kepuasan dan Loyalitas Konsumen Terhadap Tingkat

Penjualan di Warung Bu Kris (Studi Kasus Pada Ayam

Penyet Sebagai Menu Unggulan Warung Bu Kris). Jurnal

Manajemen \& Kewirausahaan Vol. 3, No. 2, September

2001: 85 - 95, Jurusan Ekonomi Manajemen, Fakultas

Ekonomi, Universitas Kristen Petra.

Wolfgang Ulaga, and Andreas Eggert, "Relationship Value and

Relationship Quality: Broadening the Nomological

Network of Business-to-Business Relationships, European

Journal of Marketing, 40 (3/4): 311-327, 2006.

Yasri, "Analisis Hubungan Jangka Panjang Nasabah dengan Bank Syariah: Studi Kasus pada Bank Syariah di Kota PadangSumatera Barat", Jurnal Aplikasi Manajemen, 4 (3): 486-493, 2006.

Yu-Hui Fang and Chao-Min Chiu, "Understanding Customers' Satisfaction and Repurchase Intentions: An Integration of IS Success Model, Trust and Justice", Internet Research, 21 (4): 479-503, 2011. 